\title{
The Effect of Mometasone Nasal Spray and/or Montelukast on Adenoid Size
}

\author{
Original \\ Article \\ Haitham Alnori', Saad Y. Sulaiman ${ }^{2}$ and Ali Abdulmuttalib Mohammed ${ }^{1}$ \\ Department of Surgery, College of Medicine, ${ }^{1}$ University of Mosul, ${ }^{2}$ Ninavah University, \\ Mosul, Iraq
}

\begin{abstract}
Background: Many pediatric patients present to the otolaryngologist with snoring and obstructive sleep apnea due to adenoid enlargement, which requires adenoidectomy. Due to the adenoid importance for immunity in early childhood, and the risks of anaesthesia and operative complications, an alternative medical treatment has been considered.

Aim: To compare the effect of mometasone spray and montelukast, each alone or in combination on the symptoms and size of obstructive adenoid in children aged 3-13 years.

Patients and Methods: A prospective randomized non-blinded study was conducted at Al-Jumhoori Teaching Hospital from August 2019 to November 2020. It included 95 patients (males 47, females 48) with nasal symptoms attributed to adenoid enlargement; they were randomly assigned to three groups; group (I) taking mometasone, group (II) taking montelukast, and group (III) taking both. Treatment continued for two months. Clinical scores were taken after two months of treatment, and then one month after cessation of treatment.

Results: In group I there was improvement at three months of nasal obstruction and adenoid size. In group II there was improvement at three months of cough only. In group III there was improvement at three months of nasal obstruction, cough and adenoid size.

Conclusions: There is significant improvement of adenoid size and symptom score with mometasone and montelukast, each alone or in combination. Mometasone has a better effect on adenoid size and symptoms than montelukast at two months, with less recurrence of adenoid size and symptoms one month after cessation of treatment. Combined therapy of mometasone and montelukast showed marginal improvement over mometasone alone at two months. At three months, there is no advantage of combined treatment over mometasone alone.
\end{abstract}

Key Words: Adenoid hypertrophy; mometasone; montelukast.

Received: 03 April 2021, Accepted: 04 June 2021

Corresponding Author: Haitham Alnori, Department of Surgery, College of Medicine, University of Mosul, Mosul, Iraq, Tel.: +964 7701637724, E-mail: haithamabdnori@uomosul.edu.iq

ISSN: 2090-0740, 2021

\section{INTRODUCTION}

Adenoid is that part of Waldeyer's Ring which is presents in the posterosuperior aspect of the nasopharynx as a collection of lymphoid tissue and plays an important role in the development of immunity in early childhood. It begins its physiological enlargement between the ages of 6-10 years, whereby at the age of 7 years it gets its largest size in relation to the volume of the nasopharynx, and then slowly atrophied by the age of 16 years ${ }^{[1,2]}$.

The adenoid is considered as a part of mucosaassociated lymphoid tissue and its exposure to multiple antigens via the mouth and nose induces naturally acquired immunity in early childhood with the resultant of B-cells production that gives rise to $\operatorname{IgG}, \operatorname{IgM}$ and IgA plasma cells ${ }^{[1,3]}$. The portal position of adenoid in the upper respiratory tract makes it an accordant reservoir of virus and bacteria causing recurrent infections which ends up with lymphoid hyperplasia. Allergic inflammation is another cause of adenoid enlargement in which the adenoid tissue will contain numerous IgE-positive mast cells ${ }^{[1,3,4]}$.
Chronic nasal obstruction due to adenoid enlargement is one of the most common children's complaints that may be associated with chronic sinusitis and recurrent otitis media, therefore adenoidectomy is considered as the most surgical procedure performed in pediatric age group ${ }^{[5]}$. The abundance of glucocorticoid receptor- $\alpha$ and cysteinyl leukotriene receptor- 1 in the adenoid tissue paved the way for non-operative treatment with nasal steroid sprays and montelukast ${ }^{[1,6]}$.

The decision on the type of treatment for adenoid enlargement depends upon the degree of airways obstruction and the associated morbidities ${ }^{[7]}$. Surgical option was chosen to reduce morbidity related to adenoid enlargement, by different surgical techniques. Although the risk/benefit analysis was done and the anesthetic/ operative complications were evaluated, complications still may occur ${ }^{[7,8]}$.

Moreover, Paulussen et $a l^{[9]}$ hypothesized that the removal of adenoid lymphatic tissue could have a depressing impact on the general immunologic system. Regrowth of 
adenoid tissue could take place after adenoidectomy ${ }^{[10]}$. The studies of Thomas et $a l^{[5]}$ and Sapthevee et $a l^{[11]}$ reported a significant revision adenoidectomy rate.

Mometasone furoate nasal spray (MF) is a local steroid that had been safely used in children above the age of 2 years old for adenoid enlargement ${ }^{[12-14]}$. This is due to the anti-inflammatory effect of steroids as it inhibits the initial inflammatory response and reduces lymphoid tissue proliferation $^{[15]}$. On the other hand, Montelukast (MO) is a cysteinyl leukotriene receptor antagonist, which can be given orally to stop the effect of leukotrienes which are inflammatory mediators present in the respiratory system $^{[16,17]}$.

The current study aims to compare the effect of MF and MO each alone or in combination on the symptoms and size of obstructive adenoid in children aged 3-13 years.

\section{PATIENTS AND METHODS}

This prospective randomized non-blinded study was adopted and conducted at Al-Jumhoori Teaching Hospital from August 2019 to December 2020. The study was approved by the scientific committee of the Department of Surgery and the Medical Research Ethics Committee at the College of Medicine/ University of Mosul, Iraq with the approval code (UOM/COM/MREC/2020(C)). Informed consent was obtained from parents before the enrolment of their children in the study.

Inclusion criteria: children aged 3-13 years who have symptoms attributed to adenoid enlargement for the last 3 months.

Exclusion criteria: children with upper or lower airway obstruction related to factors other than adenoid enlargement were excluded, as frank tonsillar enlargement, nasal septal deviation or any nasal mass, asthma, recent flu, craniofacial abnormalities. Overweight and obese children and chronically ill patients were also excluded. Another group of children ( 4 patients) have been enrolled initially in the study but excluded later due to poor compliance to treatment or due to their missing at scheduled follow-up. Patients who recently received topical nasal or systemic steroids, leukotriene inhibitors, nasal decongestants, or antihistamines were also excluded from the study.

The sample size of the study groups was calculated using the formula of equivalence clinical trial design, and was found to be equal to 30 patients for each study group according to the following equation: $\mathrm{N}=2 \times\{(\mathrm{Z} 1-$ $2 / \alpha+Z 1-\beta) / \delta 0\} 2 \times \mathrm{S} 2$ Where: $\mathrm{N}=$ size per group; $\mathrm{Z} 1-2 / \alpha$ at $0.05=1.96 ; Z 1-\beta=0.80 ; \delta 0=$ a clinically acceptable margin; $\mathrm{S} 2=$ Polled standard deviation of comparison groups.

The study included 95 patients (males 47, females 48) with nasal symptoms attributed to adenoid enlargement. They were randomly assigned to three groups according to their first attendant days; those patients who attended on Saturday/Tuesday were assigned to group one, and included 34 patients, while those patients who attended on Sunday/Wednesday were assigned to group two, and included 31 patients. The rest of the patients were assigned to group three and comprised 30 patients.

At the first visit (Visit 1) a detailed history was taken and a clinical examination was performed by one of the three authors. General history included information as age, gender and weight, and family history of atopy. Symptoms include nasal obstruction, snoring, sleep apneas, rhinorrhea and cough were asked about and each symptom is scored according to the severity from $0-3$ as follows: $0=$ symptom is absent; $1=$ symptom is mild and easily tolerated; $2=$ symptom is moderate, it is frequent and bothersome; 3 = symptom is severe presented for most of the time and interfered with daily activities and sleep. Nasal examination was performed and the adenoid is inspected by $2.4 \mathrm{~mm}$ fiberoptic nasopharyngoscope and the adenoid's size was measured relative to the nasopharyngeal airway, and graded from 1-4 according to the method described by Cassano et al where $1=$ adenoid occupies less than $25 \%$ of the nasopharyngeal airway; $2=26-50 \% ; 3=51-75 \% ; 4=$ more than $75 \%$ obstruction ${ }^{[18]}$.

Children were randomly divided into three groups as mentioned above, the first group received MF one puff in each nostril, once daily (100 microgram total) for two months. The second group was treated with MO $4 \mathrm{mg}$ chewable tablets for children aged 3-4 years, $5 \mathrm{mg}$ chewable tablets for children aged 5-8 years, and $10 \mathrm{mg}$ tablets for older children. These tablets were given once daily at bedtime for 2 months. The third group was prescribed both MF and MO for two months according to the above doses. At the end of two months, the medications of all patients were stopped.

The second visit (Visit 2) was arranged after completion of therapy i.e. after two months. Symptoms of adenoid enlargement and size of adenoid were scored similarly to the first visit. During these 2 months, some patients attended for follow-up and instructions, the rest were communicated through a phone call but no data was taken during this period. At each visit or phone call, treatment adherence had been encouraged and any adverse effects were questioned.

The third visit (Visit 3) was one month after cessation of treatment. This treatment-free month aimed to evaluate whether the improvement is sustained after cessation of treatment or not. The same parameters were measured and scored in the same way.

All the data were recorded, organized, and documented by Excel-office software. Statistical Analysis was done by (Minitab, version 18); percentages, means, standard deviations, chi-square test have been used, and the differences in group means were assessed by one-way ANOVA-test with Tukey's Pairwise comparisons to find the honest statistical differences. The $p$-value of $\leq 0.05$ was considered statistically significant. 


\section{RESULTS}

\section{I- Personal characteristics of the study sampled children}

The study included 47(49.5\%) males and $48(50.5 \%)$ females. The mean age of patients was $(6.1 \pm 2.7),(6.1 \pm 2.5)$ and $(6.2 \pm 2.3)$ years in groups I, II and III respectively. Gender percentages are almost the same among the groups with a p-value equal to 0.989 . (Table 1) shows no significant difference among the groups regarding the number of patients, age, or gender.

II- The differences among the three visits in each treatment group regarding the clinical scores of symptoms

\section{IIa- The improvement in clinical scores in group I}

(Table 2) shows differences in clinical improvement within group I patients who were taking MF among the three visits. At two months, there was significant improvement $(p$-value $=0.000)$ in nasal obstruction, cough, snoring and adenoid size. At three months, the improvement remained sustained for nasal obstruction and adenoid size only with $p$-value $=0.003,0.039$ respectively.

\section{IIb-The improvement in clinical scores in group II}

(Table 3) demonstrates differences in the clinical improvement within treatment group II patients who were taking $\mathrm{MO}$ among the three visits. At two months, there was significant improvement $(p$-value $=0.000)$ in nasal obstruction, rhinorrhea, cough, apnea and size of the adenoid. However, improvement in all scores was lost in the third visit, except for cough score which remained sustained, with $p$-value $=0.047$.

\section{IIc-The improvement in clinical scores in group III}

(Table 4) describes the differences in clinical scores within treatment group III patients who were taking MF and MO among the three visits. It portrays significant improvement of all clinical scores at two months; nasal obstruction $(p$-value $=0.000)$, rhinorrhea $(p$-value $=0.041)$, cough $(p$-value $=0.000)$, snoring $(p$-value $=0.012)$, apnea $(p$-value $=0.030)$ and size of adenoid $(p$-value $=0.012)$. At three months, the improvement is maintained for nasal obstruction $(p$-value $=0.010)$, cough $(p$-value $=0.030)$, and size of the adenoid ( $p$-value $=0.047)$.

III- The comparison among the treatment groups regarding the clinical scores of symptoms

IIIa-The mean clinical scores at the beginning of the study (visit 1)

(Table 5) demonstrates the comparisons among the treatment groups regarding the clinical scores at the beginning of the study and reveals no significant differences among their means.

\section{IIIb-The mean clinical scores after two months of treatment ( visit 2)}

(Table 6) illustrates the comparison among treatment groups regarding the clinical scores after two months and shows significant differences in favor of group I and III over group II in concerning nasal obstruction ( $p$-value $=$ III 0.007, II-III 0.015), snoring ( $p$-value $=$ II- I 0.015, II-III $0.025)$, apnea ( $p$-value $=$ II- I 0.007, II-III 0.008) and adenoid size $(p$-value $=$ II- I 0.002, II-III 0.003). Improvement in rhinorrhea was better in group II and III than group I, with $p$-value= I- II 0.035, I-III 0.003. Regarding cough, there was no significant difference among the treatment groups at two months.

\section{IIIc- The mean clinical scores one month after treatment cessation (visit 3)}

(Table 7) demonstrates the differences in means among the treatment groups one month after treatment cessation and points up that both groups I and III are doing better than group II. This difference was significant regarding nasal obstruction ( $p$-value $=$ II- I 0.002, II-III 0.003) and size of the adenoids ( $p$-value= II- I 0.009, II-III 0.004). Concerning other parameters, there is no significant difference among the three groups at visit 3 .

Table 1: Personal characteristics of the study sampled children

\begin{tabular}{|c|c|c|c|c|}
\hline Parameters & Group I Mean \pm SD & Group II Mean \pm SD & Group III Mean \pm SD & $P$-value \\
\hline No. of patients & 34 & 31 & 30 & --- \\
\hline Age (years) & $6.1 \pm 2.7 \mathrm{~A}$ & $6.1 \pm 2.5 \mathrm{~A}$ & $6.2 \pm 2.3 \mathrm{~A}$ & $0.964^{*}$ \\
\hline Male gender no. (\%) & $17(50.0)$ & $15(48.4)$ & $15(50.0)$ & $0.989^{* * *}$ \\
\hline
\end{tabular}

* One-way ANOVA-test was used. ** Chi-square test was used. 
Table 2: The improvement in clinical scores in group I, [n $=34]$

\begin{tabular}{|c|c|c|c|c|c|}
\hline \multirow{2}{*}{ Clinical scores } & \multicolumn{3}{|c|}{ Group I (MF nasal spray) } & \multirow{2}{*}{$P$-value } & \multirow{2}{*}{ Adjusted $p$-value } \\
\hline & visit (1) & visit (2) & visit (3) & & \\
\hline \multirow{2}{*}{ Nasal obstruction } & \multirow{2}{*}{$2.6 \pm 0.56^{\mathrm{A}}$} & \multirow{2}{*}{$1.0 \pm 1.09^{\mathrm{B}}$} & \multirow{2}{*}{$1.3 \pm 1.04^{\mathrm{B}}$} & \multirow{2}{*}{0.000} & $1-2 \quad 0.000$ \\
\hline & & & & & $1-3 \quad 0.003$ \\
\hline Rhinorrhea & $2.5 \pm 1.08 \mathrm{AB}$ & $1.9 \pm 1.02^{\mathrm{A}}$ & $2.2 \pm 1.11^{\mathrm{B}}$ & 0.034 & $2-3 \quad 0.035$ \\
\hline Cough & $2.2 \pm 1.17^{\mathrm{A}}$ & $1.4 \pm 1.19^{\text {в }}$ & $1.6 \pm 1.18 \mathrm{AB}$ & 0.033 & $1-2 \quad 0.031$ \\
\hline \multirow{2}{*}{ Snoring } & \multirow{2}{*}{$2.3 \pm 0.54^{\mathrm{A}}$} & \multirow{2}{*}{$1.2 \pm 0.98^{\text {в }}$} & \multirow{2}{*}{$2.0 \pm 1.15^{\mathrm{A}}$} & \multirow{2}{*}{0.000} & $1-2 \quad 0.000$ \\
\hline & & & & & $2-3 \quad 0.002$ \\
\hline Apnea & $2.4 \pm 1.25^{\mathrm{A}}$ & $1.2 \pm 1.10^{\mathrm{B}}$ & $1.9 \pm 1.18^{\mathrm{AB}}$ & 0.033 & $1-2 \quad 0.021$ \\
\hline \multirow{2}{*}{ Size of adenoid } & \multirow{2}{*}{$2.4 \pm 0.77^{\mathrm{A}}$} & \multirow{2}{*}{$1.4 \pm 0.96^{\mathrm{B}}$} & \multirow{2}{*}{$1.8 \pm 0.90^{\text {в }}$} & \multirow{2}{*}{0.000} & $1-2 \quad 0.000$ \\
\hline & & & & & $1-3 \quad 0.039$ \\
\hline
\end{tabular}

*One-way ANOVA-test with Tukey's Pairwise comparisons was used. Means that do not share a letter are significantly different.

Table 3: The improvement in clinical scores in group II, $[\mathrm{n}=31]$

\begin{tabular}{|c|c|c|c|c|c|}
\hline \multirow{2}{*}{ Clinical scores } & \multicolumn{3}{|c|}{ Group II ( MO oral tablet) } & \multirow{2}{*}{$P$-value } & \multirow{2}{*}{ Adjusted $p$-value } \\
\hline & visit (1) & visit (2) & visit (3) & & \\
\hline \multirow{2}{*}{ Nasal obstruction } & \multirow{2}{*}{$2.5 \pm 1.24^{\mathrm{A}}$} & \multirow{2}{*}{$1.8 \pm 1.19^{\mathrm{B}}$} & \multirow{2}{*}{$2.2 \pm 1.15^{\mathrm{A}}$} & \multirow{2}{*}{0.000} & $1-2 \quad 0.000$ \\
\hline & & & & & $2-3 \quad 0.005$ \\
\hline Rhinorrhea & $2.6 \pm 0.56^{\mathrm{A}}$ & $1.5 \pm 1.23^{\mathrm{B}}$ & $2.0 \pm 1.02^{\mathrm{AB}}$ & 0.000 & $1-2 \quad 0.000$ \\
\hline \multirow{2}{*}{ Cough } & \multirow{2}{*}{$2.1 \pm 1.11^{\mathrm{A}}$} & \multirow{2}{*}{$1.3 \pm 1.08^{\mathrm{B}}$} & \multirow{2}{*}{$1.5 \pm 1.10^{\mathrm{B}}$} & \multirow{2}{*}{0.010} & $1-2 \quad 0.016$ \\
\hline & & & & & $1-3 \quad 0.047$ \\
\hline Snoring & $2.4 \pm 1.20^{\mathrm{A}}$ & $1.9 \pm 1.18^{\mathrm{A}}$ & $2.1 \pm 1.15^{\mathrm{A}}$ & 0.148 & ----- \\
\hline \multirow{2}{*}{ Apnea } & \multirow{2}{*}{$2.6 \pm 0.84^{\mathrm{A}}$} & \multirow{2}{*}{$1.8 \pm 1.02^{\mathrm{B}}$} & \multirow{2}{*}{$2.2 \pm 1.06^{\mathrm{A}}$} & \multirow{2}{*}{0.000} & $1-2 \quad 0.000$ \\
\hline & & & & & $2-3 \quad 0.000$ \\
\hline \multirow{2}{*}{ Size of adenoid } & \multirow{2}{*}{$2.6 \pm 0.66^{\mathrm{A}}$} & \multirow{2}{*}{$1.9 \pm 1.23^{\mathrm{B}}$} & \multirow{2}{*}{$2.4 \pm 1.06^{\mathrm{A}}$} & \multirow{2}{*}{0.000} & $1-2 \quad 0.000$ \\
\hline & & & & & $2-3 \quad 0.026$ \\
\hline
\end{tabular}

*One-way ANOVA-test with Tukey's Pairwise comparisons was used. Means that do not share a letter are significantly different.

Table 4: The improvement in clinical scores in group III, $[\mathrm{n}=31]$

\begin{tabular}{|c|c|c|c|c|c|c|}
\hline \multirow{2}{*}{ Clinical scores } & \multicolumn{3}{|c|}{ Group III (MF and MO) } & \multirow{2}{*}{$P$-value ${ }^{*}$} & \multirow{2}{*}{\multicolumn{2}{|c|}{ Adjusted $p$-value }} \\
\hline & visit (1) & visit (2) & visit (3) & & & \\
\hline \multirow[b]{2}{*}{ Nasal obstruction } & \multirow[b]{2}{*}{$2.7 \pm 0.69^{\mathrm{A}}$} & \multirow[b]{2}{*}{$1.2 \pm 1.02^{\mathrm{B}}$} & \multirow[b]{2}{*}{$1.4 \pm 1.19^{\mathrm{B}}$} & \multirow[b]{2}{*}{0.000} & $1-2$ & 0.000 \\
\hline & & & & & $1-3$ & 0.010 \\
\hline \multirow[t]{2}{*}{ Rhinorrhea } & \multirow[t]{2}{*}{$2.4 \pm 1.23^{\mathrm{A}}$} & \multirow[t]{2}{*}{$1.2 \pm 1.10^{\mathrm{B}}$} & \multirow[t]{2}{*}{$1.9 \pm 1.13^{\mathrm{AB}}$} & \multirow[t]{2}{*}{0.040} & $1-2$ & 0.041 \\
\hline & & & & & $1-2$ & 0.000 \\
\hline \multirow[t]{2}{*}{ Cough } & \multirow[t]{2}{*}{$2.5 \pm 0.68^{\mathrm{A}}$} & \multirow[t]{2}{*}{$1.0 \pm 1.10^{\mathrm{C}}$} & \multirow[t]{2}{*}{$1.9 \pm 1.01^{\mathrm{B}}$} & \multirow[t]{2}{*}{0.000} & $1-3$ & 0.030 \\
\hline & & & & & $2-3$ & 0.003 \\
\hline Snoring & $2.2 \pm 1.05^{\mathrm{A}}$ & $1.4 \pm 1.00^{\mathrm{B}}$ & $1.8 \pm 1.13^{\mathrm{AB}}$ & 0.017 & $1-2$ & 0.012 \\
\hline Apnea & $2.3 \pm 1.09^{\mathrm{A}}$ & $1.2 \pm 1.20^{\mathrm{B}}$ & $1.8 \pm 1.16^{\mathrm{AB}}$ & 0.036 & $1-2$ & 0.030 \\
\hline \multirow{2}{*}{ Size of adenoid } & \multirow{2}{*}{$.3 \pm 0.74^{\mathrm{A}}$} & \multirow{2}{*}{$1.5 \pm 1.13^{\text {В }}$} & \multirow{2}{*}{$1.6 \pm 1.13^{\text {В }}$} & \multirow{2}{*}{0.010} & $1-2$ & 0.012 \\
\hline & & & & & $1-3$ & 0.047 \\
\hline
\end{tabular}

*One-way ANOVA-test with Tukey's Pairwise comparisons was used. Means that do not share a letter are significantly different 
Alnori et. al.,

Table 5: The mean clinical scores at the beginning of the study (visit 1)

\begin{tabular}{|c|c|c|c|c|c|}
\hline Clinical scores $^{*}$ & Group I Mean \pm SD & Group I I Mean \pm SD & Group I I I Mean \pm SD & $P$-value $e^{* *}$ & Adjusted $p$-value* \\
\hline Nasal obstruction & $2.6 \pm 0.56^{\mathrm{A}}$ & $2.5 \pm 1.24^{\mathrm{A}}$ & $2.7 \pm 0.69^{\mathrm{A}}$ & 0.170 & ----- \\
\hline Rhinorrhea & $2.5 \pm 1.08^{\mathrm{A}}$ & $2.6 \pm 0.56^{\mathrm{A}}$ & $2.4 \pm 1.23 \mathrm{~A}$ & 0.094 & ----- \\
\hline Cough & $2.2 \pm 1.17^{\mathrm{A}}$ & $2.1 \pm 1.11^{\mathrm{A}}$ & $2.5 \pm 0.68^{\mathrm{A}}$ & 0.265 & ----- \\
\hline Snoring & $2.3 \pm 0.54^{\mathrm{A}}$ & $2.4 \pm 1.20^{\mathrm{A}}$ & $2.2 \pm 1.05^{\mathrm{A}}$ & 0.687 & ----- \\
\hline Apnea & $2.4 \pm 1.25^{\mathrm{A}}$ & $2.6 \pm 0.84^{\mathrm{A}}$ & $2.3 \pm 1.09^{\mathrm{A}}$ & 0.548 & ----- \\
\hline Size of adenoid & $2.4 \pm 0.77^{\mathrm{A}}$ & $2.6 \pm 0.66^{\mathrm{A}}$ & $2.3 \pm 0.74^{\mathrm{A}}$ & 0.262 & ----- \\
\hline
\end{tabular}

* Clinical scores ranging from 0 to 3 .

**One-way ANOVA-test with Tukey's Pairwise comparisons was used. Means that do not share a letter are significantly different.

Table 6: The mean clinical scores after two months of treatment (visit 2)

\begin{tabular}{|c|c|c|c|c|c|}
\hline Clinical scores ${ }^{*}$ & Group I Mean \pm SD & Group I I Mean \pm SD & Group I I I Mean \pm SD & $P$-value $e^{* *}$ & Adjusted $p$-value \\
\hline Nasal obstruction & $1.0 \pm 1.09^{\mathrm{B}}$ & $1.8 \pm 1.19^{\mathrm{A}}$ & $1.2 \pm 1.02^{\mathrm{B}}$ & 0.025 & $\begin{array}{l}\text { II- I } 0.007 \\
\text { II-III } 0.015\end{array}$ \\
\hline Rhinorrhea & $1.9 \pm 1.02^{\mathrm{A}}$ & $1.5 \pm 1.23^{\mathrm{B}}$ & $1.2 \pm 1.10^{\mathrm{B}}$ & 0.041 & $\begin{array}{l}\text { I- II } 0.035 \\
\text { I-III } 0.003\end{array}$ \\
\hline Cough & $1.4 \pm 1.19^{\mathrm{A}}$ & $1.3 \pm 1.08^{\mathrm{A}}$ & $1.0 \pm 1.10^{\mathrm{A}}$ & 0.102 & ----- \\
\hline Snoring & $1.2 \pm 0.98^{\mathrm{B}}$ & $1.9 \pm 1.18^{\mathrm{A}}$ & $1.4 \pm 1.00^{\mathrm{B}}$ & 0.036 & $\begin{array}{l}\text { II- I } 0.015 \\
\text { II-III } 0.025\end{array}$ \\
\hline Apnea & $1.2 \pm 1.10^{\mathrm{B}}$ & $1.8 \pm 1.02^{\mathrm{A}}$ & $1.2 \pm 1.20^{\mathrm{B}}$ & 0.028 & $\begin{array}{l}\text { II- I } 0.007 \\
\text { II-III } 0.008\end{array}$ \\
\hline Size of adenoid & $1.4 \pm 0.96^{\mathrm{B}}$ & $1.9 \pm 1.23^{\mathrm{A}}$ & $1.5 \pm 1.13^{\mathrm{B}}$ & 0.042 & $\begin{array}{l}\text { II- I } 0.002 \\
\text { II-III } 0.003\end{array}$ \\
\hline
\end{tabular}

*One-way ANOVA-test with Tukey's Pairwise comparisons was used. Means that do not share a letter are significantly different

Table 7: The mean clinical scores one month after treatment cessation (visit 3)

\begin{tabular}{|c|c|c|c|c|c|}
\hline Clinical scores* & Group I Mean \pm SD & Group I I Mean \pm SD & Group I I I Mean \pm SD & $P$-value ${ }^{* * *}$ & Adjusted $p$-value \\
\hline Nasal obstruction & $1.3 \pm 1.04^{\mathrm{B}}$ & $2.2 \pm 1.15^{\mathrm{A}}$ & $1.4 \pm 1.19^{\mathrm{B}}$ & 0.008 & $\begin{array}{l}\text { II- I } 0.002 \\
\text { II-III } 0.003\end{array}$ \\
\hline Rhinorrhea & $2.2 \pm 1.11^{\mathrm{A}}$ & $2.0 \pm 1.02^{\mathrm{A}}$ & $1.9 \pm 1.13^{\mathrm{A}}$ & 0.143 & ----- \\
\hline Cough & $1.6 \pm 1.18^{\mathrm{A}}$ & $1.5 \pm 1.10^{\mathrm{A}}$ & $1.9 \pm 1.01^{\mathrm{A}}$ & 0.428 & ----- \\
\hline Snoring & $2.0 \pm 1.15^{\mathrm{A}}$ & $2.1 \pm 1.15^{\mathrm{A}}$ & $1.8 \pm 1.13^{\mathrm{A}}$ & 0.634 & ----- \\
\hline Apnea & $1.9 \pm 1.18^{\mathrm{A}}$ & $2.2 \pm 1.06^{\mathrm{A}}$ & $1.8 \pm 1.16^{\mathrm{A}}$ & 0.242 & ---- \\
\hline Size of adenoid & $1.8 \pm 0.90^{\mathrm{B}}$ & $2.4 \pm 1.06^{\mathrm{A}}$ & $1.6 \pm 1.13^{\mathrm{B}}$ & 0.011 & $\begin{array}{l}\text { II- I } 0.009 \\
\text { II-III } 0.004\end{array}$ \\
\hline
\end{tabular}

*One-way ANOVA-test with Tukey's Pairwise comparisons was used. Means that do not share a letter are significantly different 


\section{DISCUSSION}

Adenoid enlargement is considered an obstructive condition that causes significant morbidity to the child and his family. Surgical treatment in the form of adenoidectomy is the standard treatment option for persistent adenoid enlargement. Operative and anesthetic risks, together with the known incidence of recurrence of adenoid enlargement stimulated researchers to seek a more conservative $\operatorname{approach}^{[8,19]}$.

Topical nasal steroids and leukotriene inhibitors have been used increasingly for the treatment of adenoid enlargement, with conflicting evidence in the literature regarding their use alone or in combination. MF has a proved safety and efficacy in children with adenoid enlargement. In literature, many papers had studied its effect on adenoid size and symptoms. Benefits included reduction of adenoid size, improvement of symptoms, improvement of obstructive sleep apnea, and improvement of quality of life ${ }^{[14,20]}$. MO has emerged recently as an option for the treatment of adenoid enlargement. In literature, there are few papers regarding the effect of MO on obstructive adenoids. Some studies suggest using both MF and MO together ${ }^{[21,22]}$.

In the current study, we evaluated the effect of MF nasal spray and MO oral tablet each alone or in combination on the size and symptoms of adenoid (subjective and objective assessment), and discussed their effect during and after cessation of treatment. We followed patients for three months; one limitation of the current study is the lack for long term follow-up. There is no difference among the three groups regarding the number of patients in each group, age, or gender (Table1). Moreover, there is no difference among them concerning the scores of adenoid symptoms and size at the first visit (Table 5), indicating that all the three groups are well matched.

There is significant improvement in adenoid size and symptoms in all the treatment groups. At two months, group I showed improvement in all scores, except for rhinorrhea (Table 2), while group II demonstrated improvement for all scores except for snoring (Table 3). On the contrary, all scores exhibited significant improvement in group III (Table 4).

By comparing the clinical scores of the three groups at visit 2 (i.e. after two months of treatment), we found groups I and III are doing equally well, and significantly better than group II regarding nasal obstruction, snoring, apnea and size of the adenoid (Table 6). Rhinorrhea showed better response at two months to MO alone or in combination with MF than MF alone. Cough improved significantly in all the groups at two months, with no preference of one group over the others.

Clinical scores of the third visit are taken one month after cessation of treatment in all groups. This month-free interval aims to check for recurrence of symptoms or size of adenoid after cessation of treatment. Nasal obstruction and adenoid size showed significant improvement in group I and III, which remained maintained at three months with less recurrence rate than in group II. Adenoid significantly reduced in size in group I from $(2.4 \pm 0.77)$ at visitl to $(1.8 \pm 0.90)$ at visit3, $(p<0.039)$. in group III it reduced from $(2.3 \pm 0.74)$ at visit1 to $(1.6 \pm 1.13)$ at visit3, $(p<0.047)$. There is no difference at three months regarding all other parameters among the treatment groups. MO alone showed the highest recurrence rate at three months regarding all parameters, except cough. MO alone or in combination with MF didn't add significant improvement at three months when compared to MF alone (Table 7), and we believe that the improvement in group III is mainly related to MF rather than to MO.

Rhinorrhea responded better to MO or MF and MO than to MF alone, cough also showed significant improvement in groups II and III. Possibly, rhinorrhea and cough are related to an undiagnosed allergy of the upper or lower airways, which may explain their better scores in patients taking MO in groups II and III.

It seems that treatment with MO alone causes shortlived improvement in all scores except snoring, and at three months, only the score of cough is improved, while all other scores lost their improvement after cessation of MO.

Chohan et al in their meta-analysis found a significant effect of MF on nasal obstruction, snoring, apneas and size of the adenoid compared to placebo. Also, they found a smaller size of improvement in cough and rhinorrhea ${ }^{[14]}$. Our results agree with this study as we found rhinorrhea and cough responding less well to MF alone, while nasal obstruction and adenoid size have better and more sustained improvement.

Tuhanıoglu et al. studied the effect of MF, MO, or their combination on the size of adenoid, measured by lateral $\mathrm{X}$-ray of the neck, but they didn't study the recurrence after cessation of treatment. They found similar improvement in all groups with no statistical difference ${ }^{[22]}$. Our results partially agree with their findings, as we found a similar improvement during treatment, but the effect is lasting after stopping the treatment for the groups taking MF or $\mathrm{MF}$ and $\mathrm{MO}$, but not $\mathrm{MO}$ alone.

Ras et al studied the effect of MF alone or in combination with $\mathrm{MO}$ on children with obstructive adenoids. They continued treatment for three months, and then followed the patients for another three months. They found significantly better outcome with combination therapy regarding rhinorrhea, mouth breathing, snoring and adenoid-nasopharyngeal ratio. Also, they discovered less recurrence rate in the combination group than $\mathrm{MF}$ alone. However, they didn't compare the results to MO alone, while our study did. Our results don't agree with their results, as we didn't find any preference for the combination therapy over MF except for rhinorrhea at two months. 
Liu et al performed a similar comparative study to the above study of Ras et al and discovered similar findings, i.e. better outcome with combined therapy over MF alone. However, their study is also lacking the third arm of MO alone. Moreover, they didn't follow up patients after cessation of treatment as we did.

Liming et al performed a meta-analysis to study the effect of MO or MO and intranasal steroids on apnea/ hypopnea index in patients with obstructive sleep apnea ${ }^{[23]}$. The study included 668 children aged 2-5 years, and they found $\mathrm{MO}$ and intranasal steroids or $\mathrm{MO}$ alone has potential benefits for short-term management of mild pediatric OSA by reducing apnea/hypopnea index. They recommended further studies to focus on the length of treatment and persistence of the beneficial effects of therapy. Our study partially matches their results as we found significant improvement of apnea at two months in all groups, with significantly better improvement in $\mathrm{MF}$ or MF and MO groups over $\mathrm{MO}$ alone. Furthermore, we found recurrence of apnea after three months in all groups, which also agrees with the above study.

\section{CONCLUSION}

Our study found significant improvement of adenoid size and symptom score with MF and MO, each alone or in combination. MF has a better effect on adenoid size and symptoms than $\mathrm{MO}$ at two months, with less recurrence one month after cessation of treatment. The combined therapy of MF and MO showed marginal improvement over MF alone at two months. At three months, there is no advantage of combined treatment over MF alone.

\section{RECOMMENDATION}

We believe in using MF alone for the treatment of adenoid enlargement before embarking on surgical treatment. Further studies with longer follow-up period are warranted to determine the fate of adenoid after medical treatment.

\section{CONFLICT OF INTERESTS}

There are no conflicts of interest.

\section{REFERENCES}

1. Marseglia G, Caimmi D, Pagella F, Matti E, Labò E, Licari A, et al. Adenoids during Childhood: The Facts. Int J Immunopathol Pharmacol [Internet]. 2011 Oct;24(4_suppl):1-5. Available from: http://journals. sagepub.com/doi/10.1177/03946320110240S401

2. Vogler RC, Ii FJ wippol., Pilgram TK. Age-specific size of the normal adenoid pad on magnetic resonance imaging. Clin Otolaryngol Allied Sci [Internet]. 2000 Oct;25(5):392-5. Available from: http://doi.wiley. com/10.1046/j.1365-2273.2000.00381.x

3. Wysocka J, Hassmann E, Lipska A, Musiatowicz M. Naive and memory $\mathrm{T}$ cells in hypertrophied adenoids in children according to age. Int J Pediatr Otorhinolaryngol [Internet].
2003 Mar;67(3):237-41. Available from: https://linkinghub.elsevier.com/retrieve/pii/ S0165587602003749

4. Bozkurt G, Dizdar SK, Yasemin Korkut A, Uslu Coskun B. Adenoid Vegetation in Children with Allergic Rhinitis. Turk Otolarengoloji Arsivi/Turkish Arch Otolaryngol [Internet]. 2016 Mar 23;53(4):168 72. Available from: http://cms.galenos.com.tr/ Uploads/Article_43316/tao-53-168-En.pdf

5. Thomas K, Boeger D, Buentzel J, Esser D, Hoffmann $\mathrm{K}$, Jecker $\mathrm{P}$, et al. Pediatric adenoidectomy: A population-based regional study on epidemiology and outcome. Int $\mathbf{J}$ Pediatr Otorhinolaryngol [Internet]. 2013 Oct;77(10):1716-20. Available from: https://linkinghub.elsevier.com/retrieve/pii/ S0165587613003662

6. Yang D-Z, Liang J, Zhang F, Yao H-B, Shu Y. Clinical effect of montelukast sodium combined with inhaled corticosteroids in the treatment of OSAS children. Medicine (Baltimore) [Internet]. 2017 May;96(19):e6628. Available from: https://journals. lww.com/00005792-201705120-00004

7. Demirhan H, Aksoy F, Özturan O, Yıldırım YS, Veyseller B. Medical treatment of adenoid hypertrophy with "fluticasone propionate nasal drops." Int J Pediatr Otorhinolaryngol [Internet]. 2010 Jul;74(7):773-6. Available from: https://linkinghub.elsevier.com/ retrieve/pii/S0165587610001667

8. Al Sebeih K, Hussain J, Albatineh AN. Postoperative complications following tonsil and adenoid removal in Kuwaiti children: A retrospective study. Ann Med Surg [Internet]. 2018 Nov;35:124-8. Available from: https://linkinghub.elsevier.com/retrieve/pii/ S2049080118301882

9. Paulussen C, Claes J, Claes G, Jorissen M. Adenoids and tonsils, indications for surgery and immunological consequences of surgery. Acta Otorhinolaryngol Belg. 2000;54(3):403-8.

10. Duval M, Chung JC-S, Vaccani J-P. A Case-Control Study of Repeated Adenoidectomy in Children. JAMA Otolaryngol Neck Surg [Internet]. 2013 Jan 1;139(1):32. Available from: http://archotol. jamanetwork.com/article.aspx?doi=10.1001/ jamaoto.2013.1060

11. Sapthavee A, Bhushan B, Penn E, Billings KR. A Comparison of Revision Adenoidectomy Rates Based on Techniques. Otolaryngol Neck Surg [Internet]. 2013 May 8;148(5):841-6. Available from: http://journals. sagepub.com/doi/10.1177/0194599813477830

12. Bitar MA, Mahfoud L, Nassar J, Dana R. Exploring the characteristics of children with obstructive adenoid responding to mometasone fuorate monohydrate: preliminary results. Eur Arch Oto-Rhino-Laryngology [Internet]. 2013 Mar 22;270(3):931-7. Available from: http://link.springer.com/10.1007/s00405-012-2155-8 
13. Berlucchi M, Valetti L, Parrinello G, Nicolai P. Long-term follow-up of children undergoing topical intranasal steroid therapy for adenoidal hypertrophy. Int J Pediatr Otorhinolaryngol [Internet]. 2008 Aug;72(8):1171-5. Available from: https://linkinghub. elsevier.com/retrieve/pii/S0165587608001699

14. Chohan A, Lal A, Chohan K, Chakravarti A, Gomber S. Systematic review and meta-analysis of randomized controlled trials on the role of mometasone in adenoid hypertrophy in children. Int J Pediatr Otorhinolaryngol [Internet]. 2015 Oct;79(10):1599-608. Available from: https://linkinghub.elsevier.com/retrieve/pii/ S0165587615003444

15. Bhargava $\mathrm{R}$, Chakravarti A. Role of mometasone furoate aqueous nasal spray for management of adenoidal hypertrophy in children. J Laryngol Otol [Internet]. 2014 Dec 18;128(12):1060-6. Available from: https://www.cambridge.org/core/product/ identifier/S0022215114002503/type/journal_article

16. Kheirandish-Gozal L, Bandla HPR, Gozal D. Montelukast for Children with Obstructive Sleep Apnea: Results of a Double-blind Randomized Placebo-controlled Trial. Ann Am Thorac Soc [Internet]. 2016 Jul 20;13(10):AnnalsATS.201606432OC. Available from: http://www.atsjournals.org/ doi/10.1513/AnnalsATS.201606-432OC

17. Shokouhi F, Meymaneh Jahromi A, Majidi MR, Salehi M. Montelukast in Adenoid Hypertrophy: Its Effect on Size and Symptoms. Iran J Otorhinolaryngol. 2015;27(83):443-8.

18. Cassano P, Gelardi M, Cassano M, Fiorella ML, Fiorella R. Adenoid tissue rhinopharyngeal obstruction grading based on fiberendoscopic findings: a novel approach to therapeutic management. Int $\mathrm{J}$ Pediatr Otorhinolaryngol [Internet]. 2003 Dec;67(12):13039. Available from: https://linkinghub.elsevier.com/ retrieve/pii/S0165587603002556
19. Statham MM, Myer CM. Complications of adenotonsillectomy. Curr Opin Otolaryngol Head Neck Surg [Internet]. 2010 Dec;18(6):539-43. Available from: https://journals.lww.com/00020840201012000-00013

20. Ghafar MHA, Mohamed H, Mohammad NMY, Mohammad ZW, Madiadipoera T, Wang DY, et al. Mometasone furoate intranasal spray is effective in reducing symptoms and adenoid size in children and adolescents with adenoid hypertrophy. Acta Otorrinolaringológica Española [Internet]. 2020 May;71(3):147-53. Available from: https://linkinghub. elsevier.com/retrieve/pii/S0001651919301050

21. Ras AE, Hamed MH, Abdelalim AA. Montelukast combined with intranasal mometasone furoate versus intranasal mometasone furoate; a comparative study in treatment of adenoid hypertrophy. Am J Otolaryngol [Internet]. 2020 Nov;41(6):102723. Available from: https://linkinghub.elsevier.com/retrieve/pii/ S0196070920304178

22. TUHANIOĞLU B, ERKAN SO. Evaluation of the effects of montelukast, mometasone furoate, and combined therapyon adenoid size: a randomized, prospective, clinical trial with objective data. TURKISH J Med Sci [Internet]. 2017;47(6):1736-43. Available from: http://online.journals.tubitak.gov.tr/ openDoiPdf.htm?mKodu=sag-1701-179

23. Liming BJ, Ryan M, Mack D, Ahmad I, Camacho M. Montelukast and Nasal Corticosteroids to Treat Pediatric Obstructive Sleep Apnea: A Systematic Review and Meta-analysis. Otolaryngol Neck Surg [Internet]. 2019 Apr 4;160(4):594-602. Available from: http://journals.sagepub.com/ doi/10.1177/0194599818815683 